\title{
Monetary System Development and Income Distribution in Nigeria
}

\author{
MOEMEKE SCHOLASTICA EKENE \\ DEPARTMENT OF BANKING AND FINANACE, SCHOOL OF BUSINESS STUDIES, DELTA STATE \\ POLYTECHNIC, OGWASHI-UKU, DELTA STATE, NIGERIA.
}

\begin{abstract}
This study evaluates the efficacy of the monetary system via its operations and policies at reducing the level of income inequality in Nigeria over the period of 1981 to 2017. The study employs the Autoregressive Distributive Lag model estimation and the Generalized Method of Moments in light of the varying order of stationarity and nature of employed variables. The study identifies the absence of the Kuznet's U-shape trend in the Nigerian Gini coefficient and it is observed that only Credit mobilization ratio, Accessibility index and monetary policy implementation index (POX) have significant moment effect on the income distribution. While the level of credit mobilized widen the inequality gap, accessibility of financial institutions and policy implemented can be seen to be reducing the widening inequality Gap in the country. It is recommended in light of the findings that; Credit mobilization should be closely monitored to prevent insider abuse by fund custodians and administrators that might allocate credit based on nepotism. A reasonable proportion of credit should be mobilized to the low-income earners and rural dwellers. Financial Depth should be curtailed through the promotion of the cash-lite policy. This would reduce the possibility of illicit movement of funds and money laundering. It would also help in creating a more inclusive environment and accessibility to financial institutions should be further promoted for those at the grassroot level through the deployment of micro-credits and services.
\end{abstract}

Keywords: Monetary system development, financial development, income distribution, income inequality.

DOI: $10.7176 /$ RJFA/11-8-17

Publication date: April $30^{\text {th }} 2020$

\section{INTRODUCTION}

A long-standing argument in favor of the monetary system of any economy has been on its ability to mobilize financial resources and promote economic growth and development while reducing the level of income inequality over time as explained by Younsi and Bechtini (2018). The development of this sphere of the financial sector is quite critical as great scholars like Gurley and Shaw (1955); Chapra (1985); and Griffiths (1973) attest to the fact that the monetary system (i.e. the money market activities and policies) when developed is a crucial catalyst to the stimulation and promotion of any economy, especially in its developing stage like it is in Nigeria.

Unfortunately, reforms and development of the monetary system overtime could yield counter-productive results. According to Ahmed and Masih (2017), it has been observed that this sometimes leads to uneven growth or development which fuels inequality in any given economy. Typical cases could arise in which capital and funds may be accessible only by a certain group of rich individuals as predicated by their status, income level or possession of valid collateral. This magnanimously widens the gap of the income distribution.

In Nigeria, there has been a widening gap in income distribution. This has led to the purported loss of the middle-class. Despite the fact that Kuznet (1955) advocates that an economy performs better with at first with an increase in inequality followed by a decrease in inequality which gives rise to a u-shaped inverted trend in economic performance. This trend might be the reason for the current trajectory in which the Nigerian economy is on, which brings the questions for the review so as to know how well the monetary system is developed at aiding the movement of income equality.

Some related works of literature have yielded contrasting results in this area of study. Galor \& Zeira(1993); Banerjee \& Newman(1993) observed adverse relationship between monetary system development and income inequality. Other studies show evidences to support the Greenwood-Jovanovic hypothesis of an inverted u-shaped relationship between inequality and finance. Third, consistent with insights based on Kuznets (1955), the sectoral structure appears to affect how financial intermediaries impact inequality. In particular, the inequality-reducingeffects of financial intermediaries is muted in countries with larger modern (i.e., non-agricultural) sectors.

The need for a resolution as to the nature of the effect of the monetary system development on income equality constitutes the core problem of this study and largely, informs the objectives. While this study hopes to contribute to the growing body of literature on this subject matter, the results are hoped to provide valuable information for money market managers in Nigeria. In this respect, the results are hoped to provide information on the choice of peculiar monetary policy and actions that could be introduced, increased and/or modified from time to time for improved policy actions. This study is presented in four sections. Having presented an overview as above, the remaining parts are arranged in sections as follows: Section two provides the theoretical framework and review of related studies while section this study is presented in four sections three provides the materials and methods of 
analysis. Section four offers the presentation and analysis of results while section five concludes the study with discussions, conclusions, and recommendations.

\section{THEORETICAL FRAMEWORK AND LITERATURE REVIEW}

\subsection{Theoretical Framework}

Theoretical Framework on Financial Development and Inequality: Greenwood and Jovanovic (1990) introduced a non-linear relationship between money market (financial) development and inequality, which indicates an inverted U-shaped curve - at the early stage of financial development, due to limited access of credits to poor people, income disparities increase, and then after a certain stage, financial development decreases income disparities. The authors set up a model where financial development can enable people to access the information on risky investment by gathering and analyzing information so that the development of financial intermediations can contribute to diversifying the risk of the investment. Moreover, in their model, the cost of joining a financial intermediary is fixed, whereas financial intermediaries take advantage of economies of scale in screening projects. Resource allocation efficiency can be promoted by joining the financial intermediary to stimulate economic growth. In a sense, economic growth occurs when more people are able to access financial intermediaries, allowing them access to higher expected return from projects. Under the above condition, financial development affects the relationship between growth and income distribution. The inverted U-shaped hypothesis tells us the following: At low levels of economic development where financial development is less mature in their early developmental stage, fewer people are able to join financial intermediaries since the fixed costs to join are high. Thus, economic development is slow and income inequality is quite small. If financial sectors are quite well developed (more developed than at the early stage) in the middle of the developmental stage, economic growth is faster and income inequality increases more than the early stage of financial development. Lastly, if financial development is fully mature at the maturity level, income inequality will decrease again because more people can enjoy the full range of benefits from a formal financial system and be quite stable at the end.

In summary, based on the inverted U-shaped hypothesis suggested by Greenwood and Jovanovic (1990), at the early stage of economic development, financial development increases income inequality. However, as the country reaches a stage where more low-income earners have easier access to credit, income inequality will decrease. Liang's (2006) empirical analysis provides strong evidence for the linear hypothesis (Banerjee \& Newman, 1993; Galor \& Zeira, 1993). The theoretical model by Galor and Zeira (1993) studied the relationship between income distribution and macroeconomics by investment in human capital. Under the assumption that the credit market is imperfect, the wealth distribution affects aggregate output and investment activities in human capital in the short run. For this result to be effective in the long run as well, the authors added an element of nonconvexity to their theoretical model, which refers to indivisibility in investment in human capital (Jung, 2017).

When credit markets are imperfect and a fixed cost connected with schooling is high, only rich dynasties are able to invest in their human capital. Thus, an imperfect financial market system hinders the poor from accumulating human capital. In the face of a credit market's imperfections and indivisibilities in investment in human capital, the wealth distribution in conjunction with financial market imperfection influences aggregate levels of human capital and aggregate output level. If wealth distribution is not quite equal, fewer individuals accumulate human capital so that it will decrease aggregate efficiency and, thus, economic growth. In the existence of financial market imperfections, economic growth in the long run and the persistence of inequality depend on the initial wealth distribution. The theoretical model by Galor and Zeira (1993) shows that credit accessibility will increase as a financial market develops. As more low-income earners are able to borrow money to invest in their human capital, economic growth increases, and inequality is reduced.

\subsection{Empirical Framework}

Younsi and Bechtini (2018) investigated the link between financial development and income inequality in 5 developed economies of the world tagged as BRICS countries over the period of 1995 to 2015 . The study employs the panel least square and the general method of moments. The study discovers that there exists a valid long-run cointegration relationship between the considered variables. Fixed effects estimation results show that GDP per capita growth has a positive and significant effect on income inequality, while the coefficient of its squared term has a negative and significant effect on income inequality. Similarly, financial development index appears to have a positive and statistically significant effect on income inequality, while its squared term has a negative and statistically significant effect on income inequality.

Ghossoub and Reed (2017) examined the influence of financial development on income distribution in 99 economies over the period of 1990 to 2015. The study employs the Cobb Douglas function and uncovers that economies at the highest stages of financial development (economies in which money, bonds, and claims to capital are traded) experience the highest amount of capital formation and social welfare as long as inflation is low. Yet, regardless of the extent of financial development, there are generally redistributive consequences from inflation. Moreover, the model tends to predict that economies with relatively small stock markets produce the highest levels 
of income inequality.

Ahmed and Masih (2017) accessed the influence of financial development on income inequality in Malaysia within the period of 1970 to 2007. The study employed the Autoregressive distributive lag model bound estimation, the variance decomposition estimation coupled with the Granger Causality test. It was uncovered that there is a long run relationship between financial development, economic growth, trade openness and income inequality in Malaysia. However, financial development itself is found to be not statistically significant in influencing income inequality during the sample period.

Moradi, Mirzaeenejad, and Geraeenejad (2016) investigated the effect of banks and market based institutional development on income distribution of 15 selected industrialized economies from 1960 to 2010. The study employs the Fully Modified ordinary least square method. It was observed that the type of financial system affects income distribution. The market-based financial system leads to better income distribution in developed countries, while a bank-based financial system reduces income inequality in developing countries.

Nwachukwu and Besong (2015) evaluated the influence of financial intermediation and development on income inequality in 29 African economies over the period of 1990 to 2010. The study employs the vector error correction model which uncovers that; aggregate welfare is more responsive to changes in the scale rather than to the depth of financial intermediation and that there is a long-run equilibrium relationship between aggregate human welfare, financial intermediation, and income inequality.

Chen (2006) investigated the effect of monetary and financial development on the Chinese economy over the period of 1985 to 1998. The study adopts the Generalized Method of moment on 28 chinese provinces. The study discovered that China's financial intermediation development contributes to its rapid economic growth through two channels: the substitution of loans for state budget appropriation and the mobilization of household's savings, but not through loan expansion since loan distribution by financial intermediaries is inefficient.

González and Ranciere (2005) evaluated the intermediating influence of wealth on financial development and growth in 80 randomly selected countries. The study frame covers the period 1990 to 2000 . The study employs the Generalized Methods of Moment. It was discovered that the exogenous contribution of financial development on economic growth has different effects for different levels of income per capita.

Clarke, Zou, and $\mathrm{Xu}$ (2003) investigated the interrelationship between finance and income inequality in 91 economies over the period of 1960 to 1995 . The study employed the panel least square and the Generalized Methods of Moments. The study uncovers evidence that inequality decreases as economies develop their financial intermediaries, consistent with the theoretical models in Galor and Zeira (1993) and Banerjee and Newman (1993).

\section{MATERIALS AND METHODS OF ANALYSIS}

For a proper understanding of the contents, this section is split into the following sub-sections:

\subsection{Data and Variables Description:}

Time series data employed in this study are made up of the annualized values of the Gini coefficient which represents a measure of income inequality. Others consist of monetary system development dimensions such as Credit mobilization ratio, Financial Depth ratio, Accessibility Index, Policy Index, and Deposit ratio index as obtained over the period, 1981 to 2017. (37 years). The data were sourced from the World Bank Reports and Statistical Bulletin of the Central Bank of Nigeria (2017). Operational Definition of study variables

Gini coefficient: This is a statistical depiction of the level of income distribution in Nigeria over the sample study period. It was culled from the World Bank statistical report as developed by Corrado Gini (1912). It should be identified that a Gini coefficient of 0 represents an equitable distribution of income while a Gini coefficient of 1 shows a perfect inequitable income distribution.

Credit to Private sector: This is captured by the ratio of credit to private sector; to the gross domestic product in Nigeria over the study period. This variable captures the financial intermediation skill and efficiency of monetary institutions in Nigeria. A positive apriori expectation is anticipated in light of this variable and the Gini coefficient (income distribution).

Money supply ratio: This captures the control of the monetary base and is measured as the ratio of broad money supply to the gross domestic product over the study period. This variable is expected to exhibit a positive theoretical relationship to the level of the income distribution.

Accessibility index: This is captured as the growth rate of financial institution branches across the nation. It measures not only the level of accessibility to financial services but the motivational strategy of monetary institutions. Accessibility index shows a positive apriori relationship to the level of the income distribution.

Policy index: This is employed to measure the stability of monetary policy as captured by the lending rate of the monetary institutions over time. A positive apriori expectation is expected in light of this variable and the Gini coefficient (income distribution)

Deposit Rate: This captures the level of financial inclusion as induced by the monetary institutions. This is measured by the ratio of aggregate time and fixed deposit to gross domestic product in Nigeria over the study 
period. This variable is expected to be positively related to the Gini coefficient as it assists the capital formation process.

\section{Model Specification}

The study builds on the model of Clarke, Zou, and $\mathrm{Xu}$ (2003) and employs further modifications applicable to a developing economy like Nigeria. This brings about the following model:

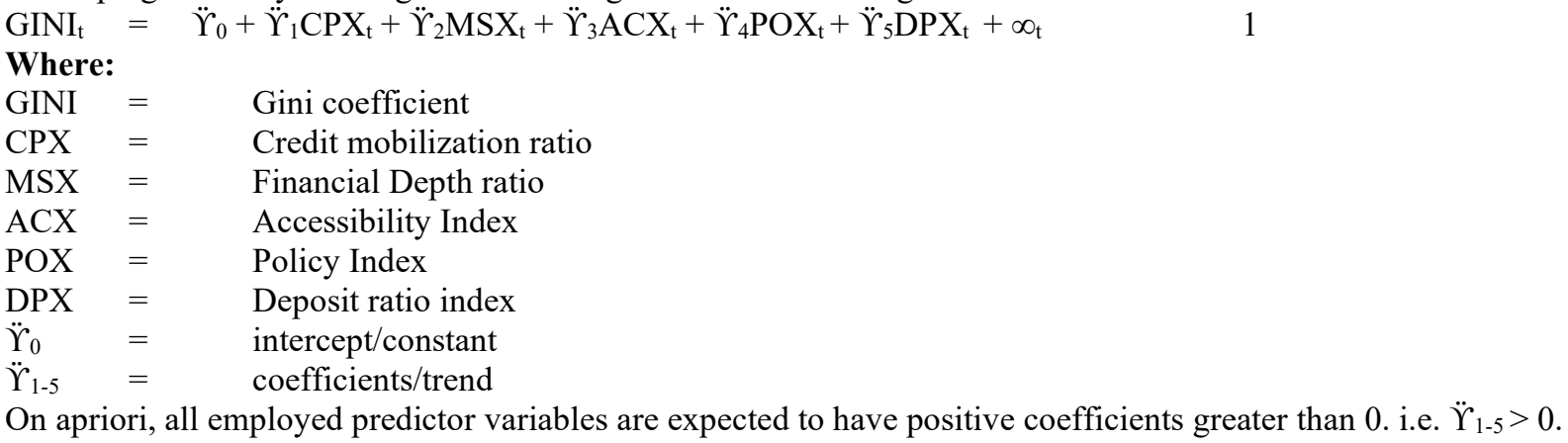

\subsection{Specification of Analytical Tools and Tests:}

Specifically focused on evaluating the interretationship between monetary system development and income equality in Nigeria, this section intends to examine the nature of prevailing relationships among the study variables. It also examines the extent to which the study variables promote and/or reinforce themselves in the growth process. For better appreciation, this sub-section is further considered as follows;

3.2.1 Stationarity (Unit Root) Test: As a pre-requisite for analysis of time series data, stationarity tests are employed to ascertain whether or not unit roots prevail. The prevalence of unit roots implies that the data set is non-stationary and its use for estimation would result in spurious estimates. The decision rule requires that the Augmented Dickey-Fuller (ADF) test statistic for the observed variables in absolute terms, must be higher than the MacKinnon's critical values at 1\%,5\%, and 10\% levels respectively according to Brooks (2009).

3.2.2 Lag Length Selection: This is a vector autoregressive selection criteria aimed at choosing the right lag for the employed study variables.

3.2.3 Auto Regressive Distributive Lag: This is a model as developed by Pesaran et al. (2001) in order to incorporate $\mathrm{I}(0)$ and $\mathrm{I}(1)$. The assumption of this model stems from the fact that it is applicable only to variables stationary at level $\mathrm{I}(\mathrm{O})$ or first difference $\mathrm{I}(1)$.

\section{PRESENTATION OF RESULTS}

The employed data, results of the tests are presented in this section as follows:

\subsection{Presentation of Data}

Employed data of the study are presented below; 
Table 1: Annual values of Gini Coefficient (GINI), Credit mobilization ratio, Financial Depth ratio, Accessibility Index, Policy Index, and Deposit ratio index in Nigeria over the period of 1981 to 2017.

\begin{tabular}{|c|c|c|c|c|c|c|}
\hline Year & $\begin{array}{c}\text { GINI } \\
\%\end{array}$ & $\begin{array}{c}\text { CPX } \\
\%\end{array}$ & $\begin{array}{c}\text { MSX } \\
\%\end{array}$ & $\begin{array}{c}\mathbf{A C X} \\
\%\end{array}$ & $\begin{array}{c}\text { POX } \\
\%\end{array}$ & $\begin{array}{c}\text { DPX } \\
\%\end{array}$ \\
\hline 1981 & 20.40 & 5.92 & 9.99 & 11.23 & 7.75 & 4.00 \\
\hline 1982 & 23.82 & 6.88 & 10.19 & 14.04 & 10.25 & 4.41 \\
\hline 1983 & 27.14 & 7.16 & 10.85 & 11.81 & 10.00 & 4.96 \\
\hline 1984 & 30.43 & 7.31 & 11.80 & 12.73 & 12.50 & 5.51 \\
\hline 1985 & 38.70 & 6.80 & 11.60 & 3.84 & 9.25 & 5.49 \\
\hline 1986 & 40.17 & 7.53 & 11.76 & 5.40 & 10.50 & 5.67 \\
\hline 1987 & 40.17 & 8.45 & 11.05 & 8.49 & 17.50 & 6.05 \\
\hline 1988 & 47.25 & 8.53 & 11.97 & 12.27 & 16.50 & 5.74 \\
\hline 1989 & 47.25 & 7.25 & 10.95 & 11.41 & 26.80 & 4.05 \\
\hline 1990 & 50.90 & 6.71 & 10.58 & 4.53 & 25.50 & 4.64 \\
\hline 1991 & 48.00 & 6.94 & 12.65 & 4.33 & 20.01 & 5.09 \\
\hline 1992 & 45.00 & 6.39 & 12.21 & 12.46 & 29.80 & 4.59 \\
\hline 1993 & 51.00 & 10.10 & 13.13 & 3.65 & 18.32 & 4.81 \\
\hline 1994 & 51.00 & 8.14 & 13.06 & 1.91 & 21.00 & 4.38 \\
\hline 1995 & 51.00 & 6.22 & 9.99 & -1.46 & 20.18 & 3.44 \\
\hline 1996 & 51.90 & 6.31 & 9.15 & 1.65 & 19.74 & 3.13 \\
\hline 1997 & 53.00 & 7.69 & 10.05 & 0.00 & 13.54 & 3.45 \\
\hline 1998 & 53.00 & 7.67 & 10.64 & -9.22 & 18.29 & 3.75 \\
\hline 1999 & 55.00 & 8.12 & 11.85 & 0.00 & 21.32 & 5.17 \\
\hline 2000 & 60.00 & 7.69 & 12.74 & 0.37 & 17.98 & 5.18 \\
\hline 2001 & 54.36 & 9.40 & 15.60 & 0.00 & 18.29 & 6.14 \\
\hline 2002 & 46.51 & 8.21 & 13.29 & 37.25 & 24.85 & 5.76 \\
\hline 2003 & 40.10 & 8.24 & 14.68 & 7.87 & 20.71 & 5.71 \\
\hline 2004 & 51.91 & 8.21 & 12.31 & 7.55 & 19.18 & 5.39 \\
\hline 2005 & 54.20 & 8.26 & 11.85 & -11.23 & 17.95 & 4.89 \\
\hline 2006 & 50.72 & 7.99 & 13.25 & 4.29 & 17.26 & 6.10 \\
\hline 2007 & 47.26 & 11.15 & 15.54 & 29.91 & 16.94 & 8.16 \\
\hline 2008 & 46.12 & 17.73 & 20.45 & 17.90 & 15.14 & 11.01 \\
\hline 2009 & 43.00 & 23.08 & 24.34 & 9.77 & 18.99 & 13.01 \\
\hline 2010 & 42.95 & 18.00 & 21.10 & 6.86 & 17.59 & 10.90 \\
\hline 2011 & 44.33 & 22.52 & 21.12 & -6.11 & 16.02 & 10.37 \\
\hline 2012 & 48.40 & 21.13 & 21.59 & 2.02 & 16.79 & 11.24 \\
\hline 2013 & 46.48 & 20.22 & 19.59 & 1.35 & 16.72 & 10.75 \\
\hline 2014 & 44.55 & 20.36 & 21.24 & -2.00 & 16.55 & 13.41 \\
\hline 2015 & 42.63 & 19.88 & 21.28 & -1.01 & 16.85 & 12.11 \\
\hline 2016 & 40.70 & 21.66 & 23.25 & 1.83 & 16.87 & 11.97 \\
\hline 2017 & 43.78 & 19.60 & 21.23 & 2.59 & 17.58 & 11.22 \\
\hline
\end{tabular}

Source: World Bank Report (2017)

Central Bank of Nigeria (2017)

\section{2: Stationarity Test}

The study proceeds to adopt the Augmented Dickey-Fuller unit toot test to evaluate and diagnose the trend of employed variables as presented in the tabular representation below: 
Table 2: Augmented Dickey Fuller Stationarity test Variables T-Stat at level (0) p-value

\begin{tabular}{|l|c|c|c|c|c|}
\hline GINI & -4.762 & 0.005 & - & - & Differencing I(1) \\
\hline CPX & -0.81532 & 0.8026 & -6.32257 & 0.0000 & $\begin{array}{c}\text { Stationarity at level (0) } \\
\text { differencing }\end{array}$ \\
\hline MSX & -0.91713 & 0.7712 & -5.60352 & 0.0000 & $\begin{array}{c}\text { Stationarity at first } \\
\text { differencing }\end{array}$ \\
\hline ACX & -4.42416 & 0.0012 & - & - & $\begin{array}{c}\text { Stationarity at level (0) } \\
\text { SOX }\end{array}$ \\
\hline POX & -2.41197 & 0.1461 & -5.90471 & 0.0000 & $\begin{array}{c}\text { Stationarity at first } \\
\text { differencing }\end{array}$ \\
\hline DPX & -0.7286 & 0.8267 & -5.10866 & 0.0002 & $\begin{array}{c}\text { Stationarity at first } \\
\text { differencing }\end{array}$ \\
\hline
\end{tabular}

Source: E-views 10 output.

The study uncovers the fact that the Gini coefficient which represents the study's measure of income and the Accessibility index (ACX) distribution passed the stationarity test at level (0). Other employed variables such as the Credit mobilization ratio (CPX), the Financial Depth ratio (MSX), the Policy Index (POX), and the Deposit ratio index (DPX) failed the stationarity test at level (0). But they attained stationarity quickly at the first differencing (I(1)). The mixture of stationarity at level (0) and first difference calls for the employment of the Autoregressive Distributive Lag (ARDL).

\section{3: Lag length selection}

A prerequisite to the ARDL test is the selection of an efficient lag for the employed model. The study, therefore, proceeds to select the appropriate lag length for the employed model.

Table 3: Lag length selection criteria

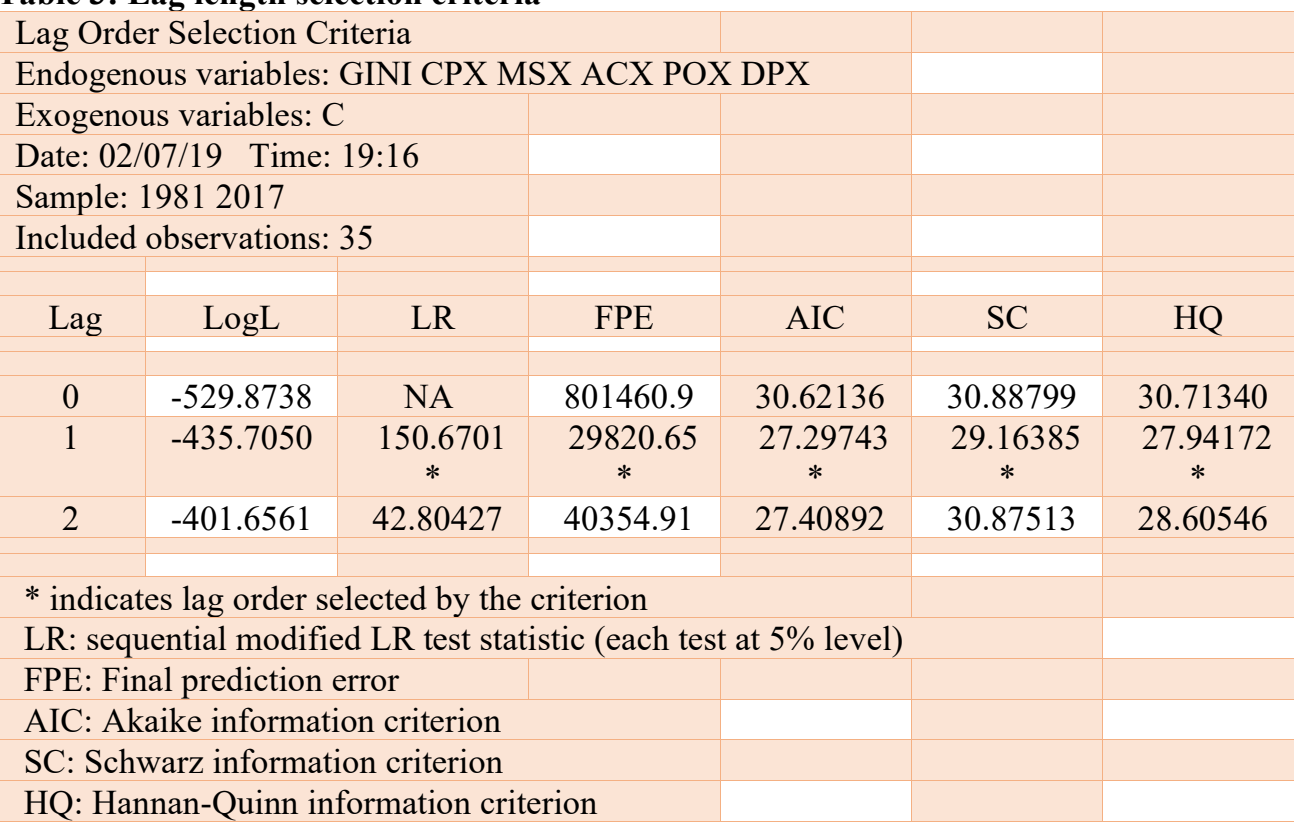

Source: E-views 10 output.

All selected criterion shows prominence and sufficiency of the first lag (1). This is justified by the signed values for all criterions (LR test, Final prediction error, Akaike, Schwarz, and Hannan-Quinn criterion). This shows that the employed ARDL will be predicated solely on the selection of 1 as the maximum lag level in further estimations. 
ARDL Model Estimation

Table 5: ARDL Model Estimation

Dependent Variable: GINI

Method: ARDL

Date: 02/07/19 Time: 19:17

Sample (adjusted): 19822017

Included observations: 36 after adjustments

Maximum dependent lags: 1 (Automatic selection)

Model selection method: Akaike info criterion (AIC)

Dynamic regressors (1 lag, automatic): CPX MSX ACX POX DPX

Fixed regressors: $\mathrm{C}$

Number of models evalulated: 32

Selected Model: ARDL(1, 0, 0, 0, 1, 0)

\begin{tabular}{crrrr}
\hline \hline Variable & Coefficient & Std. Error & t-Statistic & Prob.* \\
\hline \hline GINI(-1) & 0.717416 & 0.087287 & 8.219030 & 0.0000 \\
CPX & 0.545868 & 0.442891 & 1.232511 & 0.2280 \\
MSX & -1.101602 & 0.664847 & -1.656926 & 0.1087 \\
ACX & -0.104553 & 0.069781 & -1.498305 & 0.1452 \\
POX & -0.134234 & 0.174014 & -0.771397 & 0.4469 \\
POX(-1) & 0.346189 & 0.157075 & 2.203969 & 0.0359 \\
DPX & 0.288689 & 0.870715 & 0.331554 & 0.7427 \\
C & 18.33704 & 3.856916 & 4.754329 & 0.0001 \\
\hline \hline R-squared & 0.861569 & Mean dependent var & 45.90917 \\
Adjusted R-squared & 0.826962 & S.D. dependent var & 7.620575 \\
S.E. of regression & 3.169997 & Akaike info criterion & 5.338469 \\
Sum squared resid & 281.3687 & Schwarz criterion & 5.690362 \\
Log likelihood & -88.09244 & Hannan-Quinn criter. & 5.461289 \\
F-statistic & 24.89533 & Durbin-Watson stat & 2.148843 \\
Prob(F-statistic) & 0.000000 & & \\
\hline \hline
\end{tabular}

*Note: p-values and any subsequent tests do not account for model selection.

Source: E-views 10 output.

In light of the stationarity of employed variables at different levels, the above ARDL estimation shows that the past and present values of the criterion and predictor variables account for up to 86.16 percent of the variation in the income distribution of the Nigerian economy as observed from the R-square value. The F-statistics value (24.89533) and its probability level of 0.0000 shows a good and fitted model. This goes to show that the employed dimensions despite theoretical fitting are suited in predicting the behavior of income distribution as capsulated in the GINI coefficient.

Relative statistics: The study observes that the Financial Depth Ratio (MSX), Accessibility Index (ACX) and Policy Index (POX) shows adverse/negative coefficients to the level of the income distribution. This shows that an increase in these stipulated variables is capable of reducing the GINI coefficient/income distribution gap. All other employed variables show positive coefficients and are seen to be capable of fueling the level of income gap disparity, given the fact that a lower Gini coefficient is more desirable than a higher Gini coefficient. Only past values of employed policies (POX) showed significant influence in the prediction of the income discrepancies in the economy. The study proceeds to test for the presence of the long run relationship, as carried out in the following subsection.

\section{ARDL Bounds Test}

To evaluate the presence of a long-run relationship in the Autoregressive model employed, the study employs the ARDL Bounds test as presented below. 
Table 6: ARDL bounds Test estimation

ARDL Long Run Form and Bounds Test

Dependent Variable: D(GINI)

Selected Model: ARDL(1, 0, 0, 0, 1,0)

Case 2: Restricted Constant and No Trend

Date: 02/07/19 Time: 19:17

Sample: 19812017

Included observations: 36

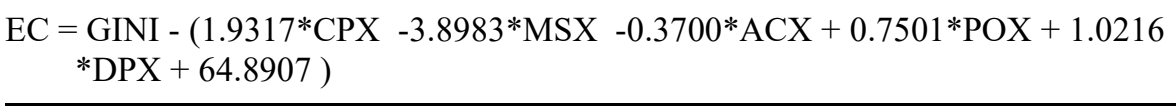

\begin{tabular}{|c|c|c|c|c|}
\hline \multirow{2}{*}{$\begin{array}{l}\text { F-Bounds Test } \\
\text { Test Statistic }\end{array}$} & \multirow[b]{2}{*}{ Value } & \multicolumn{3}{|c|}{ Null Hypothesis: No levels relationship } \\
\hline & & Signif. & $\mathrm{I}(0)$ & $\mathrm{I}(1)$ \\
\hline & & \multicolumn{3}{|c|}{$\begin{array}{l}\text { Asymptotic: } \\
n=1000\end{array}$} \\
\hline F-statistic & 6.978173 & $10 \%$ & 2.08 & 3 \\
\hline \multirow[t]{4}{*}{$\mathrm{K}$} & 5 & $5 \%$ & 2.39 & 3.38 \\
\hline & & $2.5 \%$ & 2.7 & 3.73 \\
\hline & & $1 \%$ & 3.06 & 4.15 \\
\hline & 36 & \multicolumn{3}{|c|}{$\begin{array}{l}\text { Finite Sample: } \\
\qquad \mathrm{n}=35\end{array}$} \\
\hline \multirow{3}{*}{ Actual Sample Size } & & $10 \%$ & 2.331 & 3.417 \\
\hline & & $5 \%$ & 2.804 & 4.013 \\
\hline & & $1 \%$ & 3.9 & 5.419 \\
\hline
\end{tabular}

Source: E-views 10 output.

The above table shows a bounds F-statistics value of 6.978173. This value is seen to be greater than all tabulated values at all levels (i.e. $1 \%, 2.5 \%, 5 \%$, and 10\%). This goes to show evidence of a significant long-run relationship in the Autoregressive model employed. In practical terms, this connotes that there is a significant spillover influence and trend between the dimensions of the Nigerian monetary system and the income distribution trend.

\section{ARDL Error Correction Model}

Due to the presence of a significant long-run relationship as exhibited by the ARDL bounds test, the study further proceeds to evaluate for the long run effects of employed variables and the error correction mechanism. 
Table 7: ARDL Error correction model estimation

ARDL Error Correction Regression

Dependent Variable: D(GINI)

Selected Model: ARDL(1, 0, 0, 0, 1, 0)

Case 2: Restricted Constant and No Trend

Date: 02/07/19 Time: 19:17

Sample: 19812017

Included observations: 36

ECM Regression

Case 2: Restricted Constant and No Trend

\begin{tabular}{crlrl}
\hline \hline Variable & Coefficient & Std. Error & t-Statistic & \multirow{2}{*}{ Prob. } \\
\hline \hline & Conditional Error Correction Regression & \\
\hline Variable & Coefficient & Std. Error & t-Statistic & Prob. \\
\hline C & 18.33704 & 3.856916 & 4.754329 & 0.0001 \\
GINI(-1) & -0.282584 & 0.087287 & -3.237400 & 0.0031 \\
CPX & 0.545868 & 0.221491 & 2.464021 & 0.0280 \\
MSX & -1.101602 & 0.664847 & -1.656926 & 0.1087 \\
ACX & -0.104553 & 0.034781 & -3.006038 & 0.0152 \\
POX(-1) & 0.211955 & 0.061155 & 3.465865 & 0.0447 \\
DPX & 0.288689 & 0.870715 & 0.331554 & 0.7427 \\
D(POX) & -0.134234 & 0.174014 & -0.771397 & 0.4469 \\
CointEq(-1)* & -0.282584 & 0.048595 & -5.815021 & 0.0000 \\
\hline \hline R-squared & 0.526258 & Mean dependent var & 0.649444 \\
Adjusted R-squared & 0.512325 & S.D. dependent var & 4.119392 \\
S.E. of regression & 2.876726 & Akaike info criterion & 5.005135 \\
Sum squared resid & 281.3687 & Schwarz criterion & 5.093109 \\
Log likelihood & -88.09244 & Hannan-Quinn criter. & 5.035840 \\
Durbin-Watson stat & 2.148843 & & & \\
\hline \hline
\end{tabular}

* p-value incompatible with t-Bounds distribution.

Source: E-views 10 output.

In the long-run, the error correction mechanism (i.e. cointEQ(-1)) shows that the short and long run dynamic discrepancies can be adjusted for back to equilibrium by approximately $28.26 \%$. The negative sign of the error correction coefficient reaffirms the model's convergence.

It is observed on a larger scale that the predictive nature of the model reduced greatly in the long run. This means that when the monetary system and income distribution factor are exposed to environmental factors, the predictive ability of the monetary system activities and policies only accounts for $52.63 \%$ of the variation in the level of income distribution in the Nigerian economy.

In the long run, the nations income distribution is greatly stimulated by its past value in the place of the GINI(1), followed by the Credit mobilized to the private sector. Although the positive coefficient of this relationship shows that the credit mobilized to the private sector fuels the widening gap in the inequitable distribution of income. A reason for this might be the incessant granting of loans by the financial institutions to their most preferred customers due to non-official and sentimental reason with little respect for equitable income distribution. Accessibility index (ACX) can be observed to reduce the level of inequitable distribution based on its negative and significant influence on the GINI coefficient. Also identified is the fact that the immediate past value of the Policy implementation (POX) significant influences the distribution of income (Gini coefficient). Its negative coefficient shows that present inequality in the national distribution of income is usually corrected by past policies. This shows a slightly slow manifest in the nature of policy efficiency in the country. Other monetary system factors such as the Financial Depth ratio (MSX) and Deposit ratio index (DPX) show weak influence on the level of income distribution which shows the possibility of a great percent of financial inclusion. This can also be explained in light of the fact that the nature of deposits and money supply in the nation are largely attributed to a few income groups and is not evenly spread across the study population. 


\section{Generalized Method of Moments}

Due to the nature of study variables, the study further employs the Generalized Method of Moments to capture the timely influence of the monetary systems instrumental variables on the level of income distribution (Gini coefficient). The study proceeds to present the GMM output below.

\section{Table 8: Generalized Method of Moments estimation}

Dependent Variable: GINI

Method: Generalized Method of Moments

Date: 02/07/19 Time: 18:11

Sample: 19812017

Included observations: 37

Linear estimation with 1 weight update

Estimation weighting matrix: HAC (Bartlett kernel, Newey-West fixed

bandwidth $=4.0000$ )

Standard errors \& covariance computed using estimation weighting matrix

Instrument specification: CPX MSX ACX POX DPX

Constant added to instrument list

\begin{tabular}{crlrl}
\hline \hline \multicolumn{1}{c}{ Variable } & Coefficient & Std. Error & t-Statistic & Prob. \\
\hline \hline C & 25.58667 & 11.21131 & 2.282220 & 0.0295 \\
CPX & 0.294953 & 0.116012 & 2.542435 & 0.0202 \\
MSX & 0.658195 & 0.873642 & 0.753391 & 0.4569 \\
ACX & -0.371229 & 0.156123 & -2.377796 & 0.0238 \\
POX & -1.071785 & 0.453061 & -2.365654 & 0.0244 \\
DPX & -0.486373 & 1.204142 & -0.403917 & 0.6890 \\
\hline \hline R-squared & 0.697998 & Mean dependent var & 45.21973 \\
Adjusted R-squared & 0.517030 & S.D. dependent var & 8.605055 \\
S.E. of regression & 6.570173 & Sum squared resid & 1338.182 \\
Durbin-Watson stat & 1.216230 & J-statistic & $1.35 \mathrm{E}-41$ \\
Instrument rank & 6 & & \\
\hline \hline
\end{tabular}

Source: E-views 10 output.

The Generalized Method of Moment shows that over time, the employed dimensions of the development of the monetary system account for up to $69.80 \%$ of the variation in the timely nature of the distribution of income (Gini coefficient). In light of momentous effect, a similar result can be identified with the long-run output of the ARDL test which shows that; only Credit mobilization index (CPX), Accessibility index (ACX) and policy implementation index (POX) have significant moment effect on the income distribution. While the level of credit mobilized widen the inequality gap, accessibility of financial institutions and policy implemented can be seen to be reducing the widening inequality Gap in the country.

Credit mobilization ratio (CPX): The positive coefficient of the CPX (0.294953) shows its nature as a poor income distribution agent. It can be explained that an increase in credit mobilization is increasing the Gini coefficient, therefore, showing a rising level of inequality. Its significant influence shows its prominence as a predictor of the income distribution in Nigeria.

Financial Depth ratio (MSX): The positive coefficient of the Financial Depth ratio shows that the level of money circulation is linked to a heightened level of income distribution inequality. This can be traced to the ability of illicit activities to thrive outside the banking sector in form of currency transactions. A typical example is the "Money in Ghana must go syndrome". Although it's insignificant influence of the Gini coefficient shows how poor the level of money supply predicts the distribution of income.

Accessibility Index (ACX): The negative coefficient value of -0.37123 shows that the more individuals have access to the financial institution, the less the level of inequality and better equitable distribution of income. The significant nature of the accessibility index shows the potentials financial institutions have at shrinking the level of income inequality by making their services available to many middle and low-class earners, especially in the urban areas.

Policy Index (POX): The policy implemented by the financial institutions goes to show for a fact that the monetary policies are effective. The negative coefficient of -1.071785 shows for a fact the ability for well-timed polies to clamp on the inequality in income distribution.

Deposit ratio index (DPX): The moment coefficient -0.48637 shows the potential inherent in the increase in deposit base and capital formation exercise of the financial institutions to reduce income inequality. But its 
insignificant influence shows its untapped nature.

Kuznet U-shaped Hypothesis

\section{GINI}

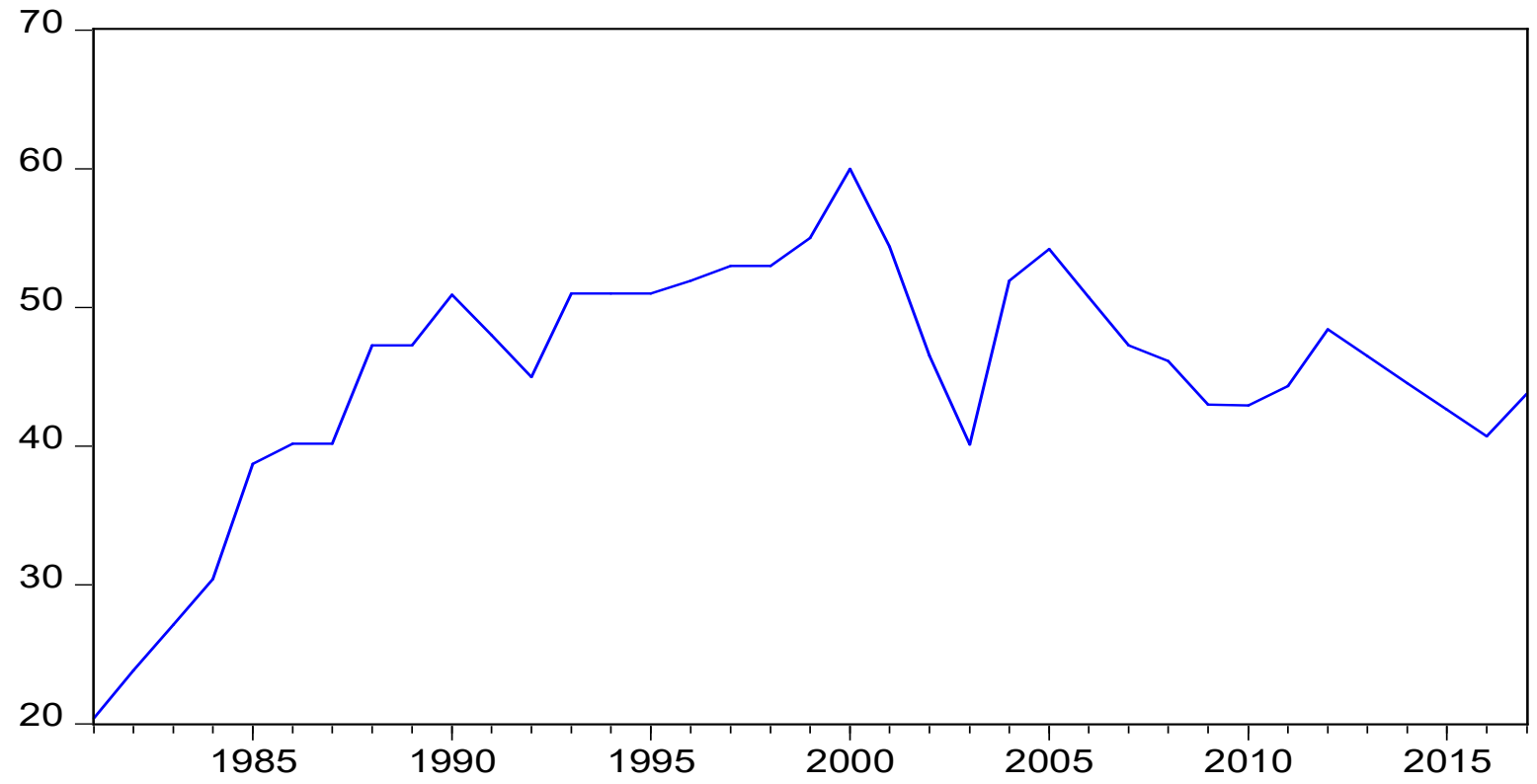

Figure 1: Gini Coefficient trend in Nigeria

Source: E-views 10 output.

The above trend in the Nigerian Gini coefficient shows, without doubt, the absence of a U shaped trend in the income distribution trend as predicted by the Kuznets U-shaped theory. This shows that the nature of inequality in Nigeria is quite abnormally skewed. And inequality is easily noticed in the middle of the trend rather than at the beginning of the trend.

\section{CONCLUSION AND RECOMMENDATIONS}

The study uncovers the significant influence of the monetary system development on income distribution in Nigeria, especially in the period of review. The study gives credence to similar studies by Banerjee and Newman (1993) and Galor and Zeira (1993) who predicted an inverse relationship between monetary system development and income distribution although, the linear hypothesis is not fully satisfied based on some positive moment influence of the credit mobilization exercise of the financial institutions. Kuznets also predicted the failure of credit mobilized by advocating that such relationship is expected in economies with small agricultural sector focus and a larger focus on modern activities like the oil and gas sector. The study fails to justify the inverted-U shape hypothesis.

There is evidence of abuse in the monetary system. This is most evident by the fact that the credit mobilization factor is seen to be promoting the level of income inequality. This result shows for a fact the dormant role of the money supply and deposit base as agents of the income distribution. This means that the monetary and financial institutions might not be actively intermediating from the surplus to the deficit unit. Rather, there is the possibility of financial institutions moving funds from the surplus units back to the surplus unit. This also points to the presence of a great level of financial exclusion in the monetary system.

\section{Recommendations}

In light of the moment effect of the employed variables, the study proposes policies that could further correct the misapplication and shortcoming of the employed dimensions of the monetary system.

- Credit mobilization should be closely monitored to prevent insider abuse by fund custodians and administrators that might allocate credit based on nepotic reasons. A reasonable proportion of credit should be mobilized to the low-income earners and rural dwellers.

- Financial Depth should be curtailed through the promotion of the cash-lite policy. This would reduce the possibility of illicit movement of funds and money laundering. It would also help in creating a more inclusive environment.

- Accessibility to financial institutions should be further promoted / provided to those at the grass-root level via the deployment of micro-credits and services. Financial institution customers should also be educated on the existing services provided by financial institutions in order to achieve the goal of accessibility of 
various monetary and financial institutions.

- Policy implementations should be done to prevent counter productivity. This could be in the form of better rates to enable expansionary rates while avoiding the inflation trap associated with these rates.

- In terms of the deposit base, banks need to stimulate public interest in deposit by increasing the deposit rate applicable to the time and fixed deposits.

\section{REFERENCES}

Ahmed, A. R., \& Masih, M. (2017). What is the link between financial development and income inequality? Evidence from Malaysia. MPRA Paper No. 79416.

Banerjee, A. V., \& Newman, A. F. (1993). Occupational choice and the process of development. Journal of political economy, 101(2), 274-298.

Brooks, C. (2009). Introductory econometrics for finance, Cambridge: Cambridge University Press, 337-339.

Chapra, M. U. (1985). Towards a just monetary system (Vol. 8). International Institute of Islamic Thought (IIIT).

Chen, H. (2006). Development of financial intermediation and economic growth: The Chinese experience. China Economic Review, 17(4), 347-362.

Clarke, G. R., Zou, H. F., \& Xu, L. C. (2003). Finance and income inequality: test of alternative theories (Vol. 2984). World Bank Publications.

Donatella, B., \& Claudio, M. (2015). Financial deepening and income distribution inequality in the euro area (No. 316).

Galor, O., \& Zeira, J. (1993). Income distribution and macroeconomics. The review of economic studies, 60(1), $35-52$.

Ghossoub, E. A., \& Reed, R. R. (2017). Financial development, income inequality, and the redistributive effects of monetary policy. Journal of Development Economics, 126, 167-189.

Gini, C. (1912). Italian: Variabilità e Mutabilità (Variability and Mutability). Cuppini, Bologna.

González, A. G., \& Ranciere, R. (2005). Wealth, Financial Intermediation and Growth (No. 2005-02).

Greenwood, J., \& Jovanovic, B. (1990). Financial development, growth, and the distribution of income. Journal of political Economy, 98(5, Part 1), 1076-1107.

Griffiths, B. (1973). The development of restrictive practices in the UK monetary system. The Manchester School, 41(1), 3-18.

Gurley, J. G., \& Shaw, E. S. (1955). Financial aspects of economic development. The American Economic Review, 45(4), 515-538.

Kuznets, S. (1955). Economic growth and income inequality. The American economic review, 45(1), 1-28.

Liang, Z. (2006). Financial development, growth and regional disparity in post-reform China (No. 2006/90). Research Paper, UNU-WIDER, United Nations University (UNU).

Moradi, Z. S., Mirzaeenejad, M., \& Geraeenejad, G. (2016). Effect of bank-based or market-based financial systems on income distribution in selected countries. Procedia Economics and Finance, 36, 510-521.

Nwachukwu, J., \& Besong, J. (2015). Financial Intermediation, Income Inequality and Welfare in Sub-Saharan Africa. A Thesis presented to the University of Central Lancashire.

Pesaran, M. H., Shin, Y., \& Smith, R. J. (2001). Bounds testing approaches to the analysis of level relationships. Journal of applied econometrics, 16(3), 289-326.

Younsi, M., \& Bechtini, M. (2018). Economic Growth, Financial Development, and Income Inequality in BRICS Countries: Does Kuznets' Inverted U-Shaped Curve Exist?. Journal of the Knowledge Economy, 1-22. 